\title{
Universiteit
}

Leiden

The Netherlands

\section{The technology and ecology of Lesotho's highland hunter-gatherers: A case study at Sehonghong rock shelter}

Pargeter, J.; Dusseldorp, G.L.

\section{Citation}

Pargeter, J., \& Dusseldorp, G. L. (2022). The technology and ecology of Lesotho's highland hunter-gatherers: A case study at Sehonghong rock shelter. Quaternary International, 611-612, 138-149. doi:10.1016/j.quaint.2020.10.019

Version:

Publisher's Version

License:

Licensed under Article 25fa Copyright Act/Law (Amendment Taverne)

Downloaded from: https://hdl.handle.net/1887/137803

Note: To cite this publication please use the final published version (if applicable). 


\title{
The technology and ecology of Lesotho's highland hunter-gatherers: A case study at Sehonghong rock shelter
}

\author{
Justin Pargeter ${ }^{\mathrm{a}, \mathrm{b}, *}$, Gerrit Dusseldorp ${ }^{\mathrm{c}, \mathrm{d}}$ \\ ${ }^{a}$ Department of Anthropology, New York University, New York, USA \\ ${ }^{\mathrm{b}}$ Rock Art Research Institute, School of Geography, Archaeology and Environmental Studies, University of the Witwatersrand, Johannesburg, South Africa \\ ${ }^{\mathrm{c}}$ Faculty of Archaeology, Leiden University, Leiden, the Netherlands \\ ${ }^{\mathrm{d}}$ Palaeo-Research Institute, University of Johannesburg, South Africa
}

\section{A R T I C L E I N F O}

\section{Keywords:}

Lesotho

LGM

Pleistocene Later Stone Age

Sehonghong

Economic intensification

Lithic technology

\begin{abstract}
A B S T R A C T
Here we evaluate the hypothesis that during cold climatic phases, people and resources became increasingly packed along highland Lesotho's riverine corridors as the viability of palatable grasslands for large mammal hunting on the upland plateaus declined. These intensification efforts resulted in increased reliance on lowerranked aquatic (fish) resources with knock-on effects for lithic technological organization. We compare data on the relative contribution of fishing to the diets of highland hunter-gatherers at Sehonghong rockshelter with a faunal proxy widely argued to correlate with subsistence intensification (faunal assemblage evenness). In addition, we compare these data with two measures of lithic technological intensification (cutting edge production and core reduction intensity) to test whether diet intensification tracks technological intensification. We show that at Sehonghong, aquatic resource exploitation is not always correlated with faunal assemblage evenness. We find that some layers (i.e. RF) show spikes in aquatic resource use irrespective of changes in faunal assemblage evenness. Other layers (i.e. RBL/CLBRF) were intensively occupied, but they do not have many fish. Our data also demonstrate that aquatic resource use is not correlated with lithic technological intensification. These results suggest that while aquatic resource exploitation was a 'fallback' option for some of Lesotho's highland hunter-gatherers, there is considerable variability. Our data show that multiple intensification dimensions were variably combined through the Late Pleistocene at Sehonghong as they were elsewhere in southern Africa.
\end{abstract}

\section{Introduction}

The volatile Late Pleistocene ( $\sim 125-12 \mathrm{ka})$ climate had variable but dramatic effects on local environments that human foraging societies depended on. Patterning in climate and its effects on resource availability are among the critical influences on hunter-gatherer behavioral variability (Kelly, 2013). The second half of the Late Pleistocene sees significant human behavioral variability under conditions of marked environmental and ecological change (Soffer and Gamble, 1990; Barton et al., 2007). Archeologists have long argued that this period witnessed changes in social and technological organization to cope with subsistence intensification analogous to processes seen in recent hunter-gatherers (e.g., Binford, 2001). Yet, few African regions contain robust records of human occupation from this period to test hypotheses about social and technological change and its relationships to subsistence intensification (see, for example, Mackay et al., 2014; Pleurdeau et al., 2014).

In southern Africa, MIS 3 ( $\sim 60-29 \mathrm{ka})$ and the early part of MIS 2 $(\sim 29-20 \mathrm{ka})$ witness an important reorganization of lithic technology. Middle Stone Age systems based on blade production and prepared core technology are gradually replaced by Later Stone Age miniaturized flake and blade technologies (Wadley, 1993; Mitchell, 2008). The production of small stone tools is a form of 'intensification', an effort to recover more cutting edge from smaller tool materials. Some archeologists have argued that the regularity with which small stone tools appear from Later Pleistocene times onward reflects increasing human population densities and smaller foraging ranges or territory sizes (Marean, 2016; Tryon and Faith, 2016). Such contexts may have provided selective pressures for toolmakers to invest more energy in tool production to continue reaping sufficient energetic returns from resource patches (cf.

\footnotetext{
* Corresponding author. Department of Anthropology, New York University, New York, USA.

E-mail addresses: justin.pargeter@nyu.edu (J. Pargeter), g.l.dusseldorp@arch.leidenuniv.nl (G. Dusseldorp).
} 
Herzog and Goodale, 2019). Alternatively, miniaturized technologies may have been adaptations to life in already marginal or unpredictable foraging patches (Mackay and Marwick, 2011).

Here we test if the subsistence intensification observed at Sehonghong is related to global cooling phases as suggested by Stewart and Mitchell (2018a: 179, 189). In addition, and outside of the scope of Stewart \& Mitchell's initial hypothesis, we test whether these relationships co-occur with intensification in the site's lithic technologies. Stewart and Mitchell (2018a) propose that decreased ungulate carrying capacity during cold climatic phases (Last Glacial Maximum [LGM: 23-19 ka] and Antarctic Cold Reversal [ACR: 14.5-13 ka]) drove demographic, land use, and lithic reorganization with effects seen in Sehonghong's aquatic resource intensification. To test Stewart \& Mitchell's main hypothesis, we compare their fish:mammal ratio to a measure of faunal assemblage evenness, which some archaeologists argue correlates with subsistence intensification. We then compare these dietary measures with two measures of lithic technological intensification (cutting edge production and core reduction intensity) to test whether dietary intensification tracks technological intensification.

\section{Background}

\subsection{The selective pressures on Lesotho's highland hunter-gatherers}

Eastern Lesotho is one of southern Africa's most climatically extreme regions (Bawden and Carroll, 1968). Stewart et al. (2012, 2016, 2018a) develop a push-pull population model to explain the shifting occupation patterns of this climatically and topographically extreme area. They propose that during climatically unstable and arid periods, Lesotho's mountains functioned as a refugium for groups from lower-lying regions. Their model suggests that under stadial conditions, hunter-gatherers used the Senqu or Orange River Valley and its lower tributaries more intensively relative to warmer periods because they offered plentiful lithic materials, reliable supplies of fuel, plant foods, and animals (cf. Carter, 1977; Plug, 1998). Building from this model, Stewart and Mitchell (2018a) argue that people and resources became increasingly limited to highland Lesotho's riverine corridors as the viability of palatable grasslands for ungulates and thus large mammal hunting on the upland plateaus declined. They hypothesize that hunter-gatherers' focus shifted to the intensive procurement of lower ranked, but more easily captured aquatic foods, such as fish (cf. Binford, 2001: 368; Kelly, 2013). This reconfiguration of highland groups towards the more intensive use of aquatic resources and riverways provided the selective pressures for the region's occupants to adopt more "specialized, efficient, and reliable" multicomponent "microlithic" technologies (Stewart and Mitchell, 2018a: 194). Such assumptions of a link between lithic technology and subsistence adaptations is often assumed (e.g. Bousman, 2005; Mackay and Marwick, 2011). The link between technological change and animal prey type needs to be clearly determined for such interpretations to hold.

Stewart and Mitchell (2018a) model draws on two behavioral ecological thresholds in hunter-gatherer subsistence defined by Binford (2001, also see Johnson, 2014). First, Binford (2001) suggests that groups should adopt more food storage to tide them over the months outside the growing season as effective temperatures (ET) (the difference between average temperatures in the coldest and warmest months) drops below 15.75. Under such seasonal temperature flucations and seasonal temperature variations, Binford (2001) predicted that hunter-gatherers would derive $>50 \%$ of their caloric intake from plant foods. When ET values dropped below 12.75, plant foods are no longer a viable option (Binford, 2001). In such cases, groups sometimes fallback on aquatic resources such as fish. Binford (2001) also predicted that subsistence intensification strategies would ratchet up if population densities approached a "packing threshold" ( 9.1 persons $/ 100 \mathrm{~km}^{2}$ Binford, 2001: 239; also see Johnson, 2014). Climates above Binford's (2001) storage threshold characterize most of modern southern Africa, except for parts of Lesotho's highland regions where ET's reach below 15.25. It is therefore probable that the region's prehistoric inhabitants dealt with seasonal food shortages by intensifying resource procurement practices.

Stewart and Mitchell (2018a) use these thresholds and contextualize Binford's (2001) data with local archeological and paleoenvironmental information from Sehonghong and its surrounding areas. They arrive at a model that generates detailed predictions about the relationship between ecological change and behavioral adaptations (Table 1). This model argues that cooling during the Last Glacial Maximum (LGM) $(\sim 24$ - $18 \mathrm{ka}$ ) and Atlantic Cold Reversal (ACR) (14.8 - 13.7) decreased highland Lesotho's effective temperatures below 12.75. Under such conditions, the Drakensberg's Afroalpine Heathland belt (cf. Mucina and Rutherford, 2006), which is dominated by the nutrient-poor grasses such as Merxmuellera disticha, would have shifted down. This would have lowered highland Lesotho's ungulate carrying capacity and decreased hunter-gatherer's encounter rates with larger prey. Stewart and Mitchell (2018a) argue that hunter-gatherers were then forced into narrower stretches of the landscape (river valleys) where populations became increasingly 'packed' and aquatic resources became a more viable subsistence intensification option.

Despite the obvious appeal of Stewart and Mitchell's (2018a) model, there are several complications in Binford's ethnographic data that are worth pointing out. First, Binford derives his data from hunter-gatherers living under very different circumstances than those in highland Lesotho. Binford's data show population packing is rare amongst modern hunter-gatherers living along riverways at altitudes $>1000$ m.a.s.l. These data also show that effective temperature is not a significant predictor of population packing $\left(\mathrm{F}(1,177)=3.8, \mathrm{p}=0.05, \mathrm{R}^{2}=0.01\right)$. Second, Binford's (2001) data show that the relationship between ET and fishing frequencies is not significant for groups living on or near rivers with ET's $<12.75\left(\mathrm{~F}(1,67)=0.66, \mathrm{p}=0.4, \mathrm{R}^{2}=0.009\right)$ (Fig. 1). The data also show no hunter-gatherers living along streams or rivers at ETs $<12.75$ and elevations similar to Sehonghong ( $>1800$ m.a.s.l) (the highest elevation in Binford's dataset with these parameters is 1083 m.a. s.l) (Fig. 1). The majority of Binford's data come from hunter-gatherers living at lower elevations between 250 and 500 m.a.s.l. These elevations are comparable to neighboring South Africa's coastal forelands. Finally, there are reasons to believe that Binford's population "packing threshold" was an implausible threshold for Lesotho's highland hunter-gatherers. In Binford's (2001) dataset, "generic hunter-gatherers" do not occur at such densities, especially at lower temperatures. These patterns are only seen amongst wealth-differentiated and ranked societies (also see Johnson, 2014). The archeological record, in our view, does not support such dense and wealth-differentiated societies occupying southern Africa during the Late Pleistocene. Recent genetic estimates of population sizes in Africa suggest much lower Pleistocene population densities (1.4 individuals per $100 \mathrm{~km}^{2}$ ) (Henn et al., 2018). These results suggest two things a) that the hypothesized

\section{Table 1}

Dates, general climatic inferences, and predictions for riverine intensification for various phases in Sehonghong's occupation. Dates are from Pargeter et al. (2017), climate and riverine intensification predictions are from Stewart and Mitchell (2018a).

\begin{tabular}{|c|c|c|c|}
\hline Layer & $\begin{array}{l}\text { Dates (kcal } \\
\text { BP) }\end{array}$ & $\begin{array}{l}\text { Climatic } \\
\text { observation }\end{array}$ & $\begin{array}{l}\text { Predicted riverine } \\
\text { occupation pattern }\end{array}$ \\
\hline BARF & $13.9-11.9$ & cooler/less humid & Intensified \\
\hline $\mathrm{RF}$ & $15.2-13.4$ & cooler/less humid & Intensified \\
\hline $\begin{array}{l}\text { RBL/ } \\
\text { CLBRF }\end{array}$ & $16.2-14.8$ & $\begin{array}{l}\text { warmer/more } \\
\text { humid }\end{array}$ & Less intensive \\
\hline BAS & $24.3-23.1$ & cooler/less humid & Intensified \\
\hline OS & $24.5-24.0$ & cooler/less humid & Intensified \\
\hline MOS & $25.9-24.0$ & cooler/less humid & Intensified \\
\hline RFS & $31.4-27.0$ & $\begin{array}{l}\text { warmer/more } \\
\text { humid }\end{array}$ & Less intensive \\
\hline
\end{tabular}



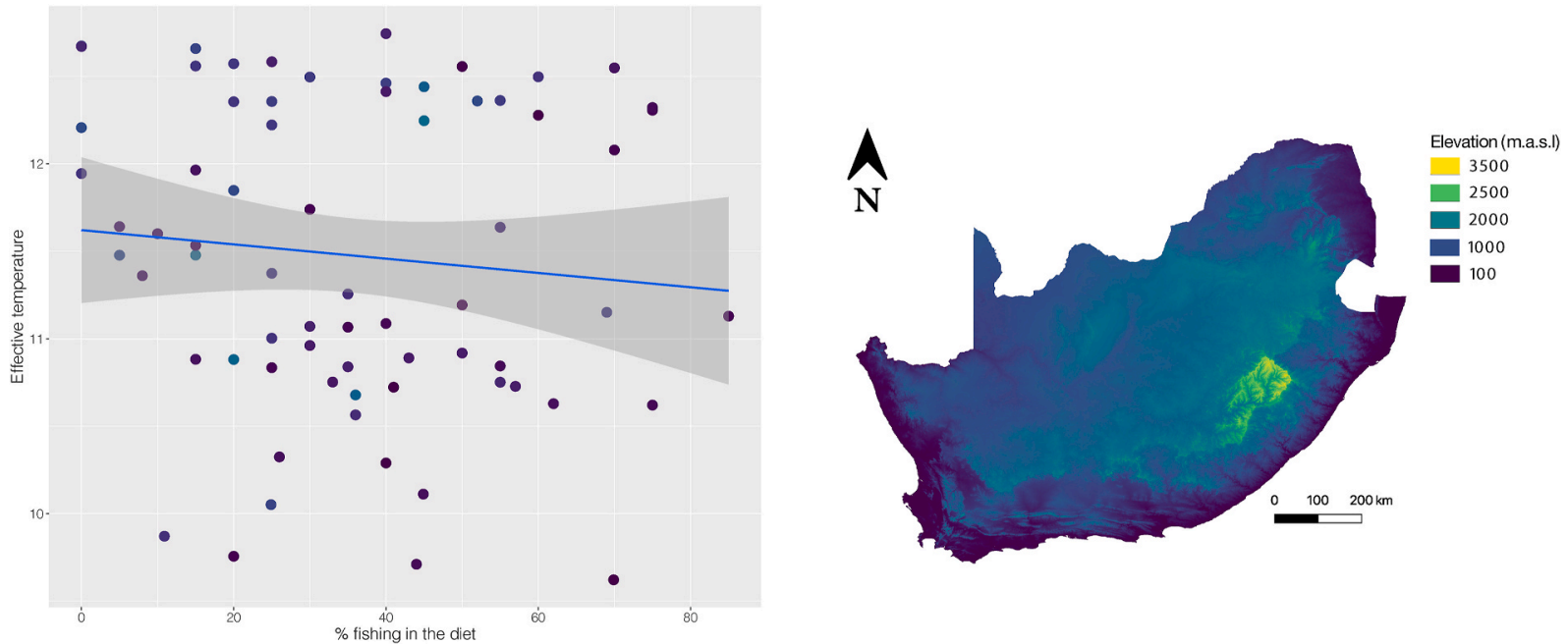

Fig. 1. Left: Binford's (2001) data showing the non-significant relationship between a region's effective temperature and a group's reliance on fishing. These data are subset for regions with effective temperatures below 12.75 and for groups living on or nearby rivers/streams; Right: Digital elevation model of South Africa and Lesotho showing areas with elevations comparable to the groups in our subset of Binford's dataset (left).

relationship between ET and fishing as an intensification strategy might not apply in highland Lesotho; and b) that the ethnographic data from which Stewart and Mitchell (2018a) build their model are not representative for the situation in highland Lesotho. For more detailed insights into these processes, it is, therefore, necessary to approach the region's existing behavioral models with data from its rich archeological

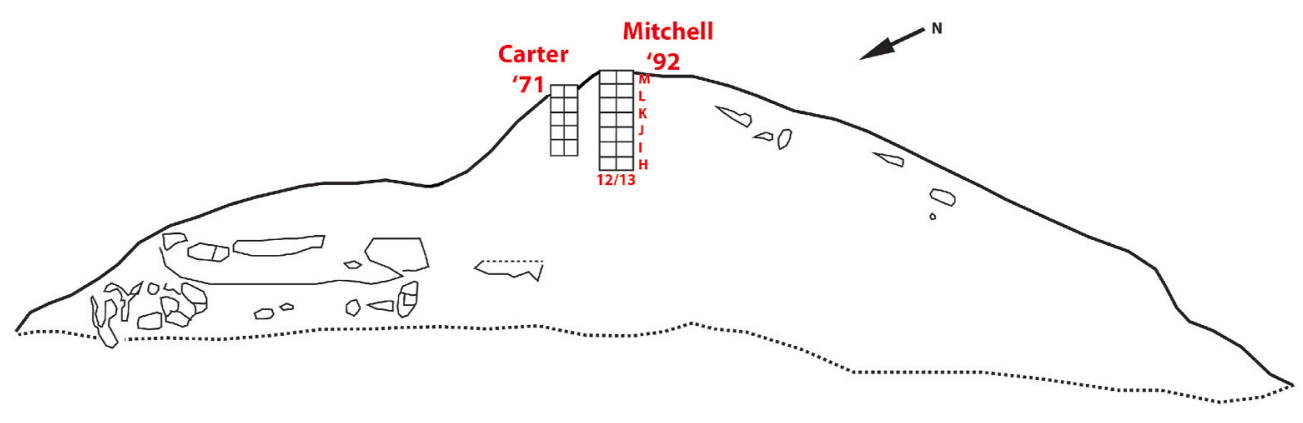

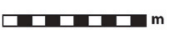

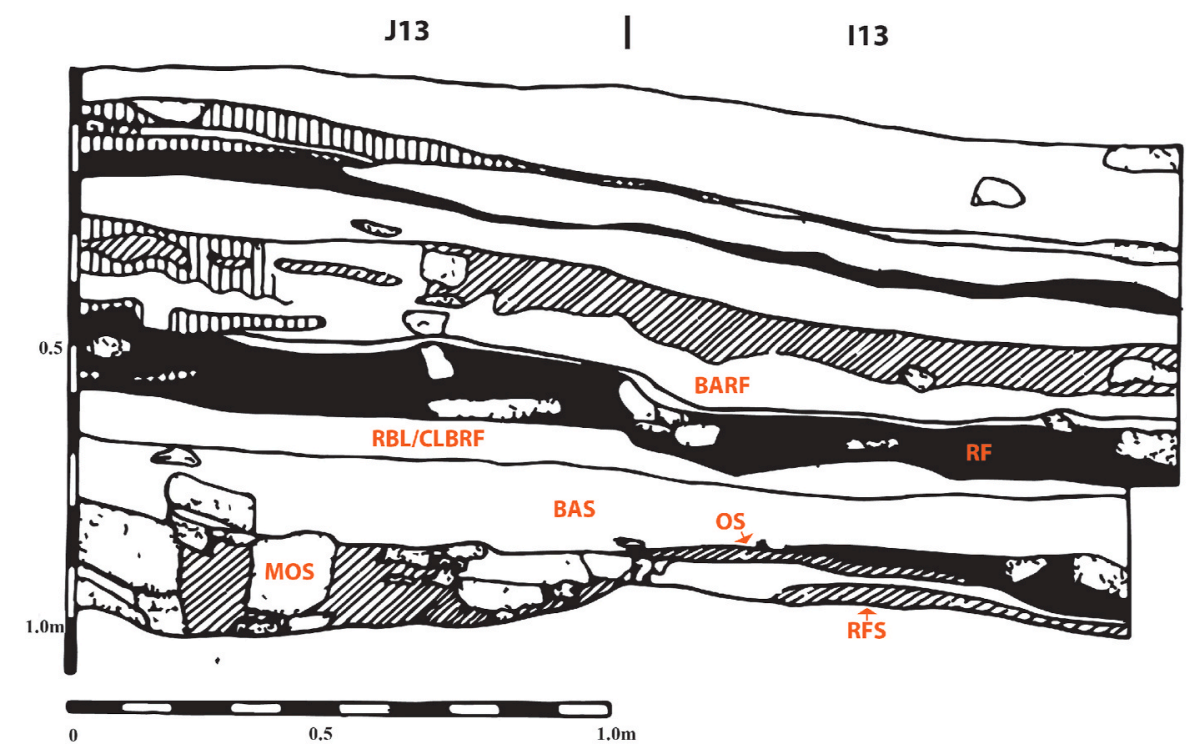

Fig. 2. Sketches showing Sehonghong's excavation plan (top) and North Wall profile (bottom). Image from Mitchell (1994, 1995). 
record. To do this, we examine aspects of lithic technology and subsistence variability at Sehonghong.

\subsection{Background to Sehonghong}

Sehonghong is a large, roughly west-facing rock shelter formed in outcropping sandstone (Fig. 2). It measures $\sim 86 \mathrm{~m}$ across the front entrance and $\sim 19 \mathrm{~m}$ from the dripline to the rear of the shelter. The site is located $20 \mathrm{~m}$ above the Sehonghong River and $\sim 1870$ m.a.s.l. in the Qacha's Nek District of Eastern Lesotho and within the modern SRZ (Carter et al., 1988). The shelter is situated on the south side of the Sehonghong River, $3 \mathrm{~km}$ upstream from where it joins the Senqu River. The site preserves a rich archeological record extending to $57.6 \pm 2.3 \mathrm{ka}$ (Jacobs et al., 2008).

Following Pat Carter's pioneering work at Sehonghong in the 1970s, Mitchell undertook further excavations in 1992 (e.g., Mitchell, 1995, 1996a, 1996b; Plug and Mitchell, 2008a, 2008b). Mitchell excavated a total of 161 stratigraphic units grouped into ten layers across his $6 \times 2 \mathrm{~m}$ excavation area. These excavations revealed a long sequence of Late Pleistocene and Holocene human occupations with the remains of abundant faunal, macro-botanical, and freshwater aquatic resources. Brian Stewart and Genevieve Dewar are currently directing excavations and re-dating of underlying deposits. All of Mitchell's excavated materials from the Late Pleistocene levels were dry sieved through $1.5 \mathrm{~mm}$ mesh. The stratigraphic layers from Mitchell's excavations include from oldest to youngest: RFS, OS, MOS, BAS, RBL/CLBRF, RF, and BARF (Pargeter et al., 2017 and Fig. 3). A combination of AMS and convention radiocarbon ages bracket these assemblages to $\sim 31.2-11.9 \mathrm{kcal} B P$ (Pargeter et al., 2017) (Table 1). Below, we outline the available information relevant to the excavation layers of interest to this project (Fig. 3). We proceed in reverse chronological order, beginning with the stratigraphically uppermost layer.

\subsection{Layer BARF (Beige Ash Above Rockfall)}

This is a thin, beige-colored, ash comprising partly decayed fine grasses which Mitchell (1995) interpreted as bedding. Mitchell (1992) assigned to BARF lithic assemblage to the Robberg Industry. These deposits are found only in the western (front) end of Mitchell's 1992 excavation trench. One conventional radiocarbon date places BARF's occupation within the Terminal Pleistocene c. 13,900-11,900 cal. BP.

\subsection{Layer RF (Rockfall)}

This layer consists of a major rockfall within and below which is a black, organic-rich loam with well-preserved macroplant remains and several grindstones. Mitchell (1995) notes that RF comprises at least three rockfall events with plant remains and artefacts interstratified between these rockfall events. He assigned RF's lithic assemblage to the Robberg Industry. Seven radiocarbon dates (five conventional, two AMS) place its occupation during the Terminal Pleistocene c. 15, 400-13,400 cal. BP (Pargeter et al., 2017).

\subsection{Layer RBL/CLBRF (Red Brown Loam/Carbonaceous Loams Below Rockfall)}

These combined layers comprise brown, compost-like light loamy soils with high macroplant contents and ashy charcoal-rich loams present only at the eastern (rear wall) end of the excavation (Mitchell, 1995). This layer contained several heavy red ochre-stained grindstones. Mitchell (1995) assigned RBL/CLBRF's lithic assemblage to the Robberg Industry. Five radiocarbon dates (three conventional, two AMS) on place the occupation of RBL/CLBRF within the Terminal Pleistocene c. 16, 200-14,600 cal. BP (Pargeter et al., 2017).

\subsection{Layer BAS (Brown Ashy Sand)}

This is a relatively thick, fine, grey/brown ashy loam from multiple occupations whose lithic assemblages Mitchell (1995) assigned to an early expression of the Robberg Industry. Mitchell (1995) equates layer BAS to the bottom of Patrick Carter's Layer IX. Pargeter et al. (2017) discuss several issues with layer BAS' dating. Their single new AMS age for layer BAS (OxA-32921, 20,600 $\pm 100 \mathrm{BP}$ [25,180-24,460 cal. BP]) is several hundred years older than the dates immediately underlying it. Two conventional ${ }^{14} \mathrm{C}$ dates place the BAS occupation further up in the sequence. The first of these conventional dates (Q-1452) is from the lower part of Patrick Carter's Layer IX and dates to 17,820 \pm 270 BP (22, $250-20,820$ cal. BP). The other conventional ${ }^{14} \mathrm{C}$ date is from Mitchell's layer BAS (Pta-6060, 15,700 \pm 150 BP [19,300-18,595 cal. BP). At present it is unclear how much of the BAS assemblage derives from the earlier LGM occupation and how much of this material is from a late/post LGM occupation. Sehonghong's data cannot currently clarify whether they represent three separate occupations and if BAS represents a complex of short-term LGM occupations. We need further dates to resolve this issue.

\subsection{Layer OS (Orange Sand)}

This is a thin, largely sterile orange sand whose lithic assemblage Mitchell (1994) assigned to the Middle to Later Stone Age (MSA/LSA) transition. Mitchell (1994) notes several small sandstone roof spalls which may represent frost-shattering associated with increased cold just before the LGM. Layer OS's features comprise mostly small shallow hearths. A single AMS radiocarbon date (24,420-23,915, OxA-32917) confirms that this layer was deposited during the early LGM (Pargeter et al., 2017).
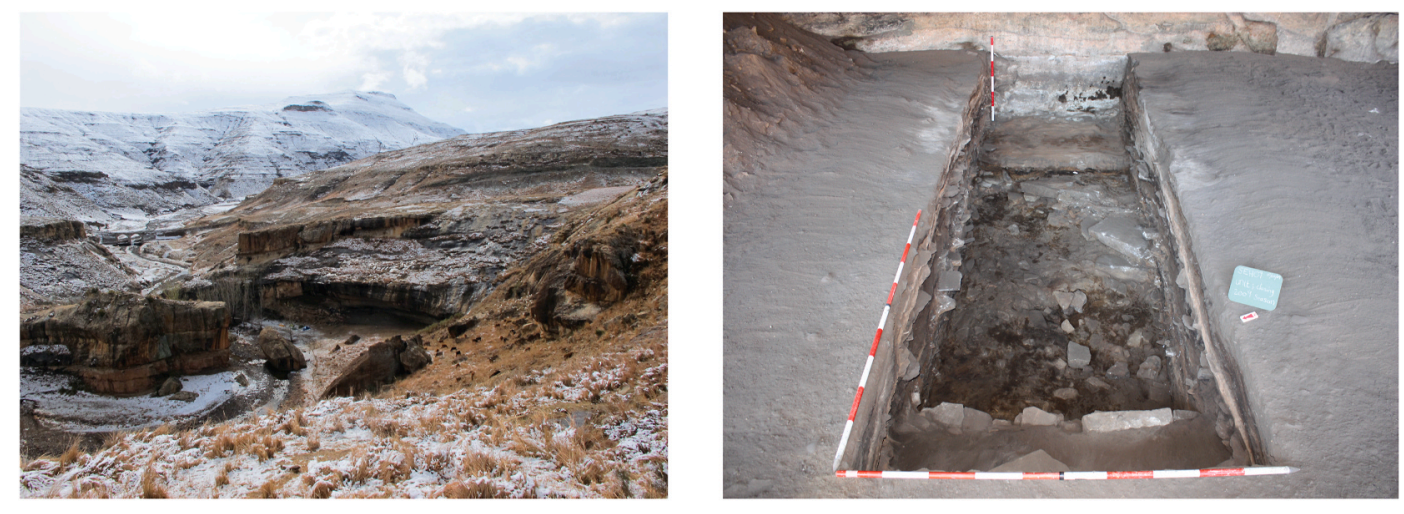

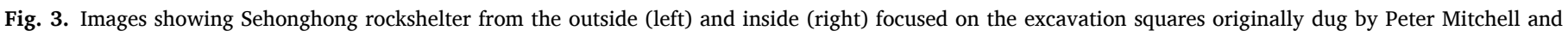
subsequently by Brian Stewart and Genevieve Dewar. Images courtesy of Brian Stewart. 


\subsection{Layer MOS (Mottled Orange Sand)}

This is a series of brown to orange sandy units comprising small sandstone spalls with extensive black and darker brown mottling (Mitchell, 1994). Most of the features present in these layers are small shallow hearths. Mitchell (1994) associated later MOS'S lithic assemblage with the MSA/LSA transition. The excavation of unit 140 in layer MOS revealed a large $150 \mathrm{~mm}$ deep pit filled with charcoal, which Mitchell (1994:17) interpreted as a, "possibly a roasting pit or some other kind of special-purpose fire". Similarly extensive charcoal features in layers BAS and RBL/CLBRF were interpreted as 'roasting pits' (Mitchell, 1995). Four radiocarbon dates (two conventional, two AMS) provide an age range of 24,900-24,100 cal. BP (Pargeter et al., 2017).

\subsection{Layer RFS (Rockfall with Sand)}

This layer is equivalent to Patrick Carter's Layer VI and represents a major episode of roof collapse (Mitchell, 1994). The deposit comprises numerous thin sandstone spalls and angular rocks. Mitchell (1994:21) notes that RFS' lithic assemblage is "microlithic in character, although with mean flake sizes slightly greater than those recorded for succeeding Sehonghong LSA assemblages". He therefore assigned the assemblage to the MSA/LSA transition. Four radiocarbon dates (two conventional and two AMS) provide an age range of c. 31,200-28,100 cal. BP. Collectively these dates indicate a substantial hiatus between layer RFS and the layers above it.

\subsection{Results from prior lithic studies}

Several studies have examined variability in lithic technologies throughout the Sehonghong sequence. Mitchell's (1994; 1995) work on the site's lithic assemblages documented long-term technological and typological trends. He described a pattern across the late Pleistocene levels RFS-RBL-CLBRF towards smaller flake production, increased bladelet production, greater flake standardization, and overall infrequent retouched tool use (with retouched tool frequencies ranging between 0.05 and $0.4 \%$ of all flakes). In contrast, the trends in bipolar technology, the use of 'formal' bladelet cresting techniques, and pyramidal bladelet core strategies were less clear.

Pargeter et al. (2017) found that higher occupation density (lithics/volume of excavated deposit) at Sehonghong did not always correlate with intensified use of local food resources as tracked by increased bipolar core reduction and relative fish consumption. They report on intensified occupations in layers BAS, but not in layers MOS and OS, which showed lower occupation density signals and elevated fish frequencies. Layer RF in fact showed reduced occupation density at times of increased fishing (Pargeter et al., 2017). Loftus et al. (2019) likewise show patterns in Sehonghong's pre-LGM ( $>24$ kcal BP) level RFS with low lithic discard intensity (lithics/year), lower core to retouched tool ratios, and a higher retouched to unretouched tool ratio. They argued that these patterns matched the theoretical expectations of individual provisioning systems (systems to equip individuals with toolkits and raw materials necessary to carry out tasks and maintain higher levels of mobility) (cf. Kuhn, 1992). Pargeter et al. (2017) highlight a series of variably dense human occupations across the terminal Pleistocene in layer RBL-CLBRF (dense occupation), layer RF (less dense) with a drop to the lowest values in layer BARF $(\sim 15-12 \mathrm{kcal} B P)$. Bipolar core frequencies were lowest in layers with evidence of increased site occupation densities (layers BAS, RBL-CLBRF, and RF) and highest in layers with the lowest occupation densities (RFS, MOS, OS, and BARF). They argued that factors other than raw material scarcity and occupation density drove these patterns. One possible factor is Sehonghong's rich and abundant high-quality silicate raw materials (see Section 2.5). Another possibility is that the area's raw material abundance led to a situation where time stress rather than raw material conservation influenced technological decisions (cf. Mitchell 1988). Shorter site visits may have driven the need for quick, functionally flexible, and simpler lithic technologies produced using otherwise "wasteful" reduction methods to save time in contexts where it was otherwise limited (cf. Mackay and Marwick, 2011).

These studies point to several concurrent patterns in Sehonghong's late Pleistocene lithic assemblage. First, variability across the assemblages likely reflects a complex interaction between paleoenvironments, landscape changes, mobility constraints, and provisioning strategies. Second, the site's bipolar core frequencies do not match the expectations of models linking expedient core technologies to site occupation density (Parry and Kelly, 1987). This mismatch is because archeologists built these models on two assumptions that do not apply at Sehonghong a) that raw materials are scarce, and b) that bipolar reduction is wasteful. Third, these previous studies suggest that aquatic resource use is not simply correlated with site occupation density nor to lithic technological changes. Several issues remain to be determined: a) are knappable rocks truly scarce around Sehonghong and b) how do the site's technological patterns and aquatic resource use intensification articulate with its rich faunal assemblage. The following sections outline the paper's methodologies to address both of these issues.

\section{Materials and methods}

\subsection{Fauna}

Previous work suggests several ways in which intensification should lead to changes in faunal assemblage composition. From this work, we derive a "taxon-free" measure (cf. Faith and Lyman, 2019) for the fauna data published by Plug and Mitchell (2008a, 2008b), to test if hunter-gatherer mammalian predation patterns correlate with intensified aquatic resource use (see also Clark and Kandel, 2013; Dusseldorp, 2014).

To test the prediction that under conditions of decreased terrestrial productivity, faunal assemblages should include lower-ranked prey types, we track the evenness of the exploited resources. Archaeologists have typically assumed faunal evenness tracks subsistence intensification. The assumption is that with increased intensification, faunal assemblage evenness should increase as hunter-gatherers exploit lowerranked prey to a greater extent (cf. Neeley and Clark, 1993).

Several studies use Shannon's index to track faunal assemblage evenness (e.g., Dusseldorp, 2012; 2016). However, Shannon's metric is strongly affected by sample size differences. Instead, we use Simpson's index calculated as $1-D^{\prime}=\sum n_{i}\left(n_{i}-1\right) / \mathrm{N}(\mathrm{N}-1)$ for finite samples (Faith and Lyman, 2019, 217). Here $n_{i}$ is the number of specimens assigned to taxon $i$, and $\mathrm{N}$ is the total sample size. Simpson index runs between 0 and 1 with lower values showing uneven assemblages (dominated by few taxa) and more even assemblages (more equitable distribution of different taxa) showing values closer to 1 . We calculated Simpson's index for Sehonghong's mammal remains using PAST 4.0 (Hammer et al., 2001, http://folk.uio.no/ohammer/past/) (See Supplementary Tables 1 and 2 and the paper's Supplementary data file). We excluded birds, herpetofauna, carnivores, and primates as they are less likely to have been targeted as prey species. Although birds were certainly included as prey elsewhere (Val et al., 2016), at Sehonghong, their numbers are small in most assemblages. Moreover, bird feces were excavated in layers BAS and RBL-CLBRF suggesting that birds roosted in the shelter and some of their remains were not brought in by people (Plug and Mitchell, 2008a, 43). We included large rodents, one of which, Otomys, is present in large numbers in some of the assemblages as the excavators aconsider them anthropogenically accumulated (Plug and Mitchell, 2008a, 36). We exclude fish remains from the calculations. Their skeletal composition is very different from that of mammals, meaning they have very different numbers of taxonomically identifiable remains per skeleton. Moreover, their bone structure is different from that of mammals leading to differential preservation compared to mammals. These factors combined lead to significantly different rates of 
skeletal part input of both classes of remains meaning they cannot be combined in a single evenness measure (Lyman, 2015, 295).

We determined the non-overlapping taxonomic categories for each assemblage adding specimens for which the original classifications were uncertain (determined to, e.g., cf. Connochaetes gnou) to that species' count. (cf. Grayson, 1991). We also omitted specimens determined to general categories unless there were no subsidiary taxonomic groups in that assemblage (e.g., Otomys sp. was excluded when specimens identified to Otomys irroratus were present but was calculated as a represented taxon in assemblages where no specimens were attributed to O. irroratus).

We compare our faunal evenness and lithic intensification data to Stewart and Mitchell's (2018a: 161) fish to mammal ratio (see Table 3). They derive this ratio by dividing the fish NISP by the combined mammal and fish NISP for each of Sehonghong's layers. Stewart and Mitchell (2018a: 161) argue that, "the latter [fish] represent a viable intensification option" for Lesotho's highland hunter-gatherers. Values above one show diets with higher relative fish contributions, while values lower than one show lower relative fish contributions. Stewart and Mitchell (2018a) argue that episodes in which Lesotho's prehistoric inhabitants used riverways more intensively correlate with increased fish to mammal ratios.

\subsection{Lithics}

Archeologists have argued that the local availability of knappable rock is onedriver of lithic technological variability (e.g. Parry and Kelly, 1987). Sehonghong's surrounding geology provides toolmakers with a seemingly abundance of cryptocrystalline silicate (CCS) rocks such as chert, chalcedony, and agate (Carter et al., 1988). These stones occur as river-borne nodules and in veins and screes around the site (Mitchell, 1996b). Cryptocrystalline silicate nodules occur in a range of sizes and morphologies with small nodules well represented; vein cherts occur in large package sizes (Fig. 4). Other local raw materials used for lithic production include dolerites and hornfels derived from eroding volcanic features. The local volcanic rocks occur in larger package sizes; they are more difficult to knap, but they create tougher flake edges.

Despite decades of archeological work in and around Sehonghong, detailed quantitative survey data on the regions' raw material distribution and abundance is lacking. To begin addressing this issue, Pargeter implemented a systematic landscape survey project designed to locate, describe, and map raw material sources around Sehonghong. The method entails the use of systematic grids of $4 \mathrm{~m} \times 4 \mathrm{~m}$ survey squares set at a $10 \mathrm{~km}^{2}$ area centered on Sehonghong (Fig. 5). We chose $10 \mathrm{~km}^{2}$ as this approximates the average forager's daily foraging radius (Kelly, 2013). Pargeter selected 100 survey squares at random from this grid (comprising approximately 1,000,000 squares) to record rock types, density, quality, and size (Fig. 5). The surveys followed an unpublished chert identification and description protocol developed by Charles Arthur and Geeske Langejaans. These squares were stratified to capture both riverine (25\%) and terrestrial (75\%) locations. This stratified random sampling strategy allowed us to construct unbiased probabilistic models of raw material distributions and densities. Here we present preliminary results from this survey with a more comprehensive report planned for the future.

\subsubsection{Lithic analyses}

We selected the archaeological lithic samples from two $1 \mathrm{~m}^{2}$ excavation squares at Sehonghong (squares K12/K13). We control for raw material variability by focusing on the region's most abundant and knappable rock type, chert. Our preliminary surveys, focused on chert, show that these rocks are abundant in the local environment. The analysis targeted a sample size of at least 300 flakes/layer (in layers with fewer than 300 lithics/layer, all were measured), and all cores were analyzed. This analysis included all flaked materials except small $(<5$ $\mathrm{mm}$ ) flake fragments without platforms. A sample size of 300 flakes per aggregate and $\sim 20-100$ cores per aggregate meets most social science disciplines' standards at the $95 \%$ confidence level (Finlay and Agresti, 1986). Our lithic sample contains representative numbers from each major stratigraphic layer and allows us to control, to some degree, the volume of excavated material in our comparisons.

Our analysis tracks strategic variability in lithic reduction processes and economic decision-making through two measures: flake cutting edge to mass ratio and the assemblage reduction intensity index (ARI) (see Table 3). The flake cutting to mass ratio is a widely used metric to trace lithic technological efficiency (e.g., Muller and Clarkson, 2016; Stout et al., 2019). Measuring technical efficiency using flake cutting edge to mass ratios is particularly relevant in a context associated with low frequencies of retouched tools and high rates of unretouched blades such as is the case with the lithic assemblages in this study. We use the calculations in Mackay (2008) (flake cutting edge = length + maximum width + maximum dimension) and Braun and Harris (2003) (flake cutting edge to mass $=$ flake cutting edge $/ \mathrm{mass}^{3}$ ) to calculate the flake cutting edge to mass ratios on our assemblage. The second formula uses an exponent to account for the non-linear relationship between edge and weight. We measured flake length from the point of initiation in the direction of percussion, maximum dimension is the longest distance across the ventral face of the flake, and maximum width is the widest point of the flake perpendicular to flake length. More efficient technological strategies should show an increase in the flake cutting edge to mass ratio, especially on small elongated flakes/blades.

The ARI represents the ratio between average flake length and average core length used to gauge the intensity of raw material use and reduction (Olszewski et al., 2011). Archeologists predict that lithic miniaturization should occur more often in contexts with intensive core reduction (e.g., Tryon and Faith, 2016). However, functional

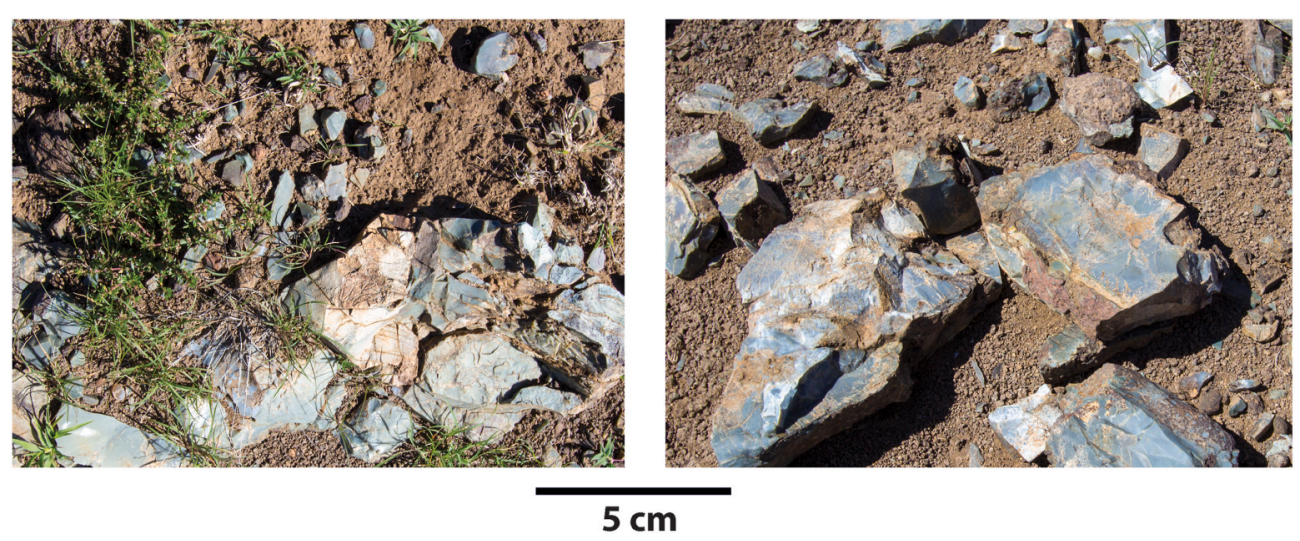

Fig. 4. Large terrestrial chert nodules found during probabilistic surveys around Sehonghong. 
A

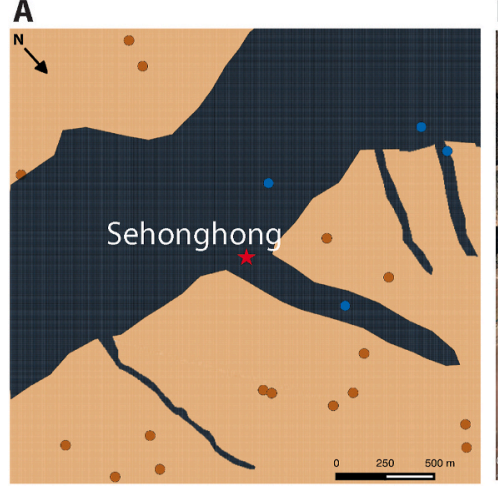

B

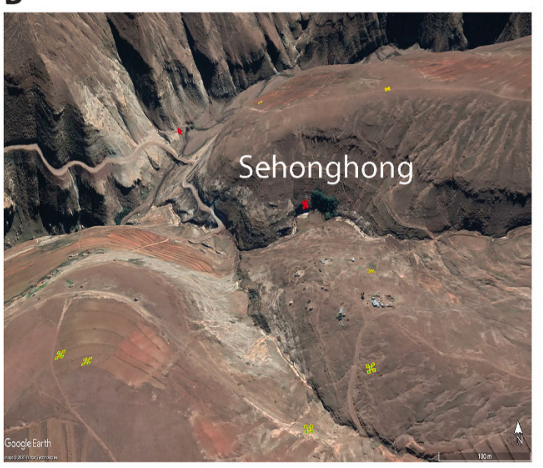

C

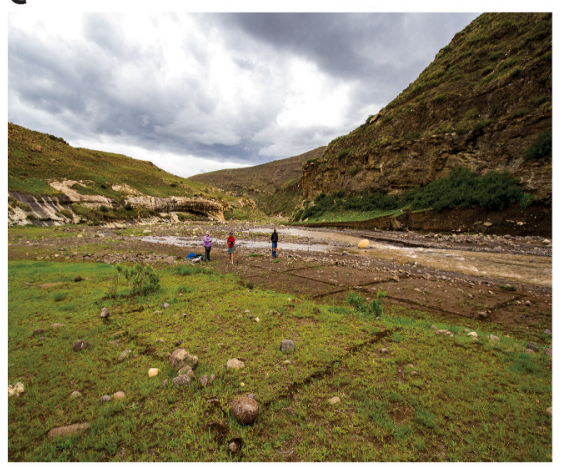

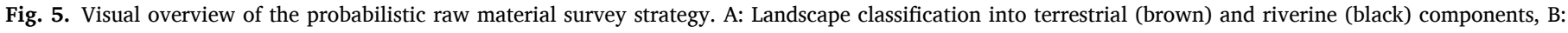

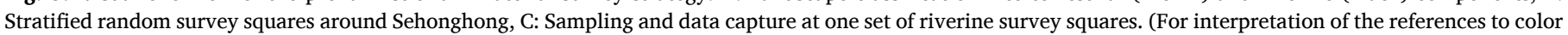
in this figure legend, the reader is referred to the Web version of this article.)

requirements might also compel toolmakers to produce smaller flakes irrespective of concerns about raw material conservation. The character of an assemblage and its degree of miniaturization may, therefore, not depend primarily on the economy of raw materials. The ARI provides a means of testing this hypothesis. The idea behind the measurement is that cores from which toolmakers have struck fewer flakes should be larger (on average) than the flakes indicating a low reduction intensity (ARI $<1$ ). On the other hand, cores that toolmakers have heavily reduced on-site will be smaller than the first flakes (ARI $>1$ ) and, if reduction proceeded on-site and was intensive enough, even lower than the average size of flakes/blades.

We expect to find several combinations of these two variables under different intensification scenarios where raw material is otherwise abundant. The obvious hypothetical response to economic intensification is for toolmakers to increase reduction intensity (ARI $>1$ ) while increasing cutting edge production. However, all technological decisions have both benefits and costs. Experiments comparing different technologies on chert show more intensive reduction strategies (i.e., bipolar reduction) produce lower cutting edge to mass (Pargeter and Eren, 2017). We are, therefore, unlikely to find situations in which both of these variables increase at the same time. A plausible scenario could involve toolmakers' use of lower reduction intensity (ARI $<1$ ) (as it is relatively straightforward to replenish raw material around Sehonghong) while achieving higher cutting edge production through systematic small elongated flake production (i.e., through freehand bladelet production strategies). This combination minimizes overall tool production and replacement times while maintaining edge quality and cutting edge production. Another compromise would be toolmakers' use of higher levels of reduction intensity (ARI $>1$ ) through techniques such as bipolar reduction while sacrificing cutting edge output (bipolar reduction tends to produce more irregular flake edges).

These two metrics track technological intensification at different levels. The cutting edge to mass ratio provides information about the nature of flaked products, while reduction intensity tracks overall core reduction efficiency. We predict that economic intensification should result in more efficient lithic reduction strategies as foragers invested in more reliable technologies, such as composite spears with smaller and more efficiently made replaceable stone components (Stewart and Mitchell, 2018a: 190). If this prediction holds, increasing evidence for lithic production efficiency should co-occur with higher faunal assemblage evenness, the increased importance of small prey, and higher fish to mammal ratios.

\section{Results}

Fig. 6 presents the chert abundance and quality data from the raw material survey squares. The data show an abundance of cherts in the squares with the terrestrial sample showing significantly greater chert abundances than the riverine sample $\left(x^{2}[1]=9.5, \mathrm{p}<0.01\right.$, Cramer's V effect size $=0.22$ ). Data on the chert qualities show significantly higher frequencies of fine cherts compared to coarse or heterogenous cherts $\left(x^{2}\right.$ $[1]=21, \mathrm{p}<0.01$, Cramer's V effect size $=0.27)$. Fine-grained cherts dominate in both the riverine and terrestrial survey squares demonstrating that knappable rock is present in appreciable quantities. The
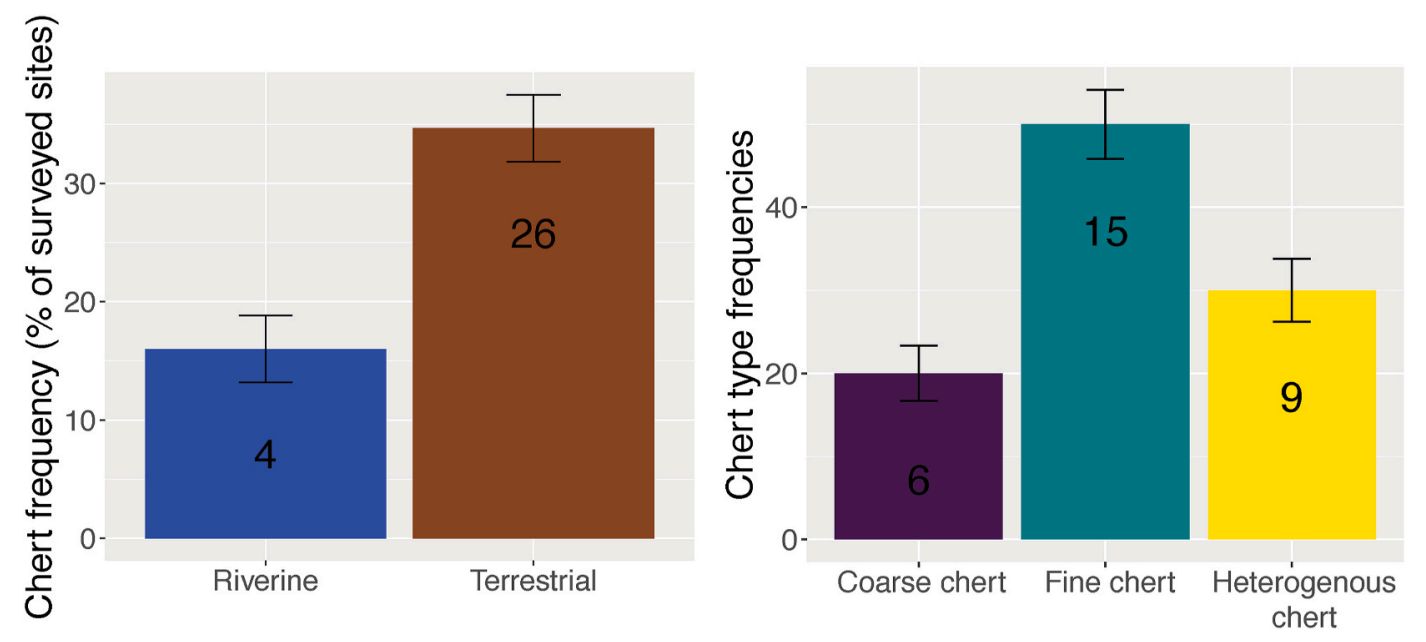

Fig. 6. Chert nodule abundance at riverine and terrestrial survey sites (left) and chert type frequencies across all sampled squares. 
chert size and mass data in Fig. 5 show the chert nodules occur in a range of package sizes, many of which fall well within a knappable size range. Table 2 presents summary statistics for the fine-grained chert nodules found across the survey squares showing their variable sizes. The preliminary Sehonghong survey results allow us to a) control to some degree for raw material abundance when comparing Sehonghong's lithic technological patterns, and b) to show that raw material economizing is unlikely to have driven prehistoric toolmaker's choices between different lithic reduction strategies.

\subsection{Faunal and lithic analyses compared}

The following sections present our results comparing Sehonghong's faunal and lithic patterns. In summary, the results show a) faunal evenness is correlated with the fish:mammal ratio mostly for layers postdating the LGM b) the fish:mammal ratio shows weak relationships with the two lithic variables, c) increased faunal assemblage evenness correlates with more intensive core reduction strategies.

Fig. 8 summarizes the relationship between our two fauna and two lithic variables across Sehonghong's seven layers. The evenness values are relatively high in layers MOS and BAS showing a more diverse large mammal procurement. Layers OS and BARF, on the other hand, show lower evenness values, which suggests a more targeted mammal procurement pattern.

The flake cutting edge to mass ratio shows a steady increase from layer MOS through to layer RBL-CLBRF with decreases in layers RF and BARF. Cutting edge values peak in layer RBL-CLBRF well after the LGM (Fig. 7). The ARI ratio shows a more variable pattern with decreased reduction intensity from layer MOS through to layer BAS. Reduction intensity values increase after that until layer BARF, where the ARI values are the lowest in the Sehonghong sequence. All the layers except MOS have ARI values below 1, showing that flakes were on average smaller than the cores from which toolmakers struck them. The data also show that toolmakers did not, on average, heavily reduce cores at the site. That said, ARI values never dip below 0.7 (the value for layer BARF), showing that average flake length still accounts for a large amount of the average core length. From this pattern, we deduce that toolmakers decided to produce smaller flakes irrespective of concerns about immediate raw material conservation. This finding matches the results from our probabilistic raw material surveys (see Fig. 6).

The relationship between the two lithic variables manifests in different ways (Fig. 8). Some layers show lower reduction intensity matched with higher cutting edge to mass production (OS and BAS), others show more moderate reduction intensity and lower cutting edge production (RFS, BARF), and others show higher reduction intensity coupled with lower cutting edge production (MOS, RBL-CLBRF, RF). Interestingly, the maximum intensification scenario (higher reduction intensity coupled with higher cutting edge production) does not occur. This result supports our earlier prediction that higher cutting edge to mass production and greater reduction intensity are unlikely to co-occur because the costs of such a combination were too high.

Table 4 shows the correlation coefficients for the lithic and fauna variables. The comparisons show mostly weak correlation coefficients suggesting few direct linkages between our lithic and fauna patterns.

\section{Table 2}

Summary metric data on chert nodules found during the probabilistic raw material surveys.

\begin{tabular}{lllll}
\hline Variable & Length $(\mathrm{mm})$ & Width $(\mathrm{mm})$ & Thickness $(\mathrm{mm})$ & Mass $(\mathrm{g})$ \\
\hline $\mathrm{N}$ & 144 & 144 & 144 & 144 \\
Min & 21.6 & 6.23 & 5.8 & 3.3 \\
Max & 103.36 & 79.62 & 88.34 & 288 \\
Median & 39.59 & 22.03 & 22.02 & 18 \\
Mean & 44.33 & 24.94 & 24.93 & 41 \\
Variance & 371.05 & 162.08 & 197.91 & 2977.3 \\
Std. Dev & 19.26 & 12.73 & 14.07 & 54.6 \\
\hline
\end{tabular}

The cutting edge to mass ratio accounts for $30 \%$ of the variance in the fauna evenness index. The ARI index accounts for $50 \%$ of the fauna evenness metric's variance with correlations most pronounced across layers MOS to BARF. This result suggests that increased faunal evenness matches a reliance on more intensive core reduction strategies and increased flake production.

Finally, using the data in Table 4 and Fig. 8, we test the hypothesis that changes in resource intensification as measured by Stewart and Mitchell's (2018a) fish:mammal ratio reflect broader technological and dietary intensification. The data show stronger correlations between the fish:mammal ratio and faunal assemblage evenness than with the two lithic metrics. The fauna evenness metric shows a positive $(0.38)$ correlation driven mostly by patterns in the layers MOS, BAS, RBL/CLBRF, and BARF. The pre-LGM layer OS shows a decline in faunal evenness at the same time as a marginal uptick in fishing, which is opposite to the predicted pattern. Layer RF, associated with the ACR, shows a large increase in fishing with no change in faunal evenness. Correlations between the fish:mammal ratio and the two lithic variables are weak with the ARI index showing a weak correlation $(-0.27)$ and the cutting edge to mass ratio showing a weak positive relationship (0.26). Overall, these results provide mixed support for Stewart and Mitchell's (2018a) aquatic resource intensification hypothesis.

\section{Discussion}

Our results demonstrate that the relationship between global climates, the (re)organization of lithic technology, and indications for subsistence intensification at Sehonghong are not straightforward. Global climatic cooling may have severely impacted highland Lesotho's local environment, but human behavioral responses appear to have been complex and variable.

Stewart and Mitchell (2018a) propose a mechanism to explain how specific global climate change affected local paleoenvironmental conditions and human subsistence/land intensification in highland Lesotho. We agree with the general expectation that ungulate carrying capacity decreases at higher altitudes and that these effects were probably more pronounced in cooler periods. If people were under subsistence stress and efforts at dietary intensification ratcheted upward, we would expect to find increased fish remains to co-occur with increased dietary evenness. As predicted, we find that some faunal assemblage evenness values increase at times when groups discard more fish at Sehonghong. Notably, we find a strong correlation between these two variables in layer BAS. The BAS pattern is important because this layer is Sehonghong's largest and densest LGM assemblage. BAS is also the oldest layer assigned to the Robberg Industry, which Stewart and Mitchell (2018a) argue represents the start of a long-term process of lithic technological reorganization. However, our inability to tease apart more detail in the current structure of the BAS assemblage (see Section 2.2) makes it difficult to determine if most of this material derives from the lower component of this layer (i.e. earlier in the LGM before conditions deteriorated in highland Lesotho) or from the upper component in this layer (i.e. later in the LGM after conditions deteriorated in highland Lesotho). Being able to do so would help us to address whether aquatic exploitation intensified under peak cool LGM conditions.

In line with Stewart and Mitchell's (2018a) observations, fish remains are also important in layer RF, deposited during the ACR. However, the faunal evenness valued for this assemblage is slightly lower than that for the preceding occupation. This runs counter to Stewart and Mitchell's (2018a) prediction, of decreasing ungulate foraging returns correlating with increased emphasis on aquatic resources. Layer RF's discard patterns suggest that, as least in some parts of highland Lesotho, fish exploitation and dietary evenness are not driven by the same mechanisms. One possible explanation is that fishing and mammal hunting occurred at different times of the year and that our current resolution is not insufficient to tease these seasonal forays apart. Stewart and Mitchell (2018a: 165) discuss the importance of scheduling fishing 
Table 3

Summary of the fauna and lithic data used in the paper.

\begin{tabular}{|c|c|c|c|c|}
\hline Layer & Cutting edge/mass (mm) & Reduction intensity & Fish:mammal ratio & Fauna assemblage evenness (Simpson 1-D) \\
\hline BARF & 54.22 & 0.64 & 1.08 & 0.73 \\
\hline $\mathrm{RF}$ & 59.14 & 0.93 & 1.94 & 0.82 \\
\hline RBL/CLBRF & 61.09 & 0.81 & 0.22 & 0.82 \\
\hline BAS & 56 & 0.76 & 2.45 & 0.85 \\
\hline OS & 54.09 & 0.85 & 0.72 & 0.80 \\
\hline MOS & 51.45 & 1.14 & 0.45 & 0.85 \\
\hline RFS & 52.67 & 0.88 & 0.08 & 0.72 \\
\hline
\end{tabular}
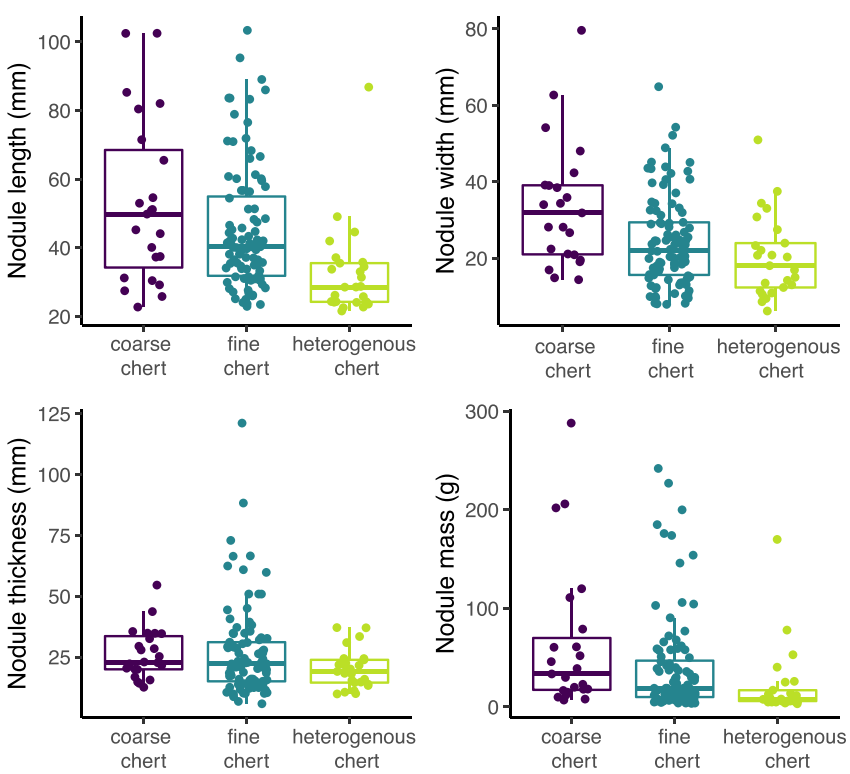

Fig. 7. Chert nodule sizes compared across chert types.

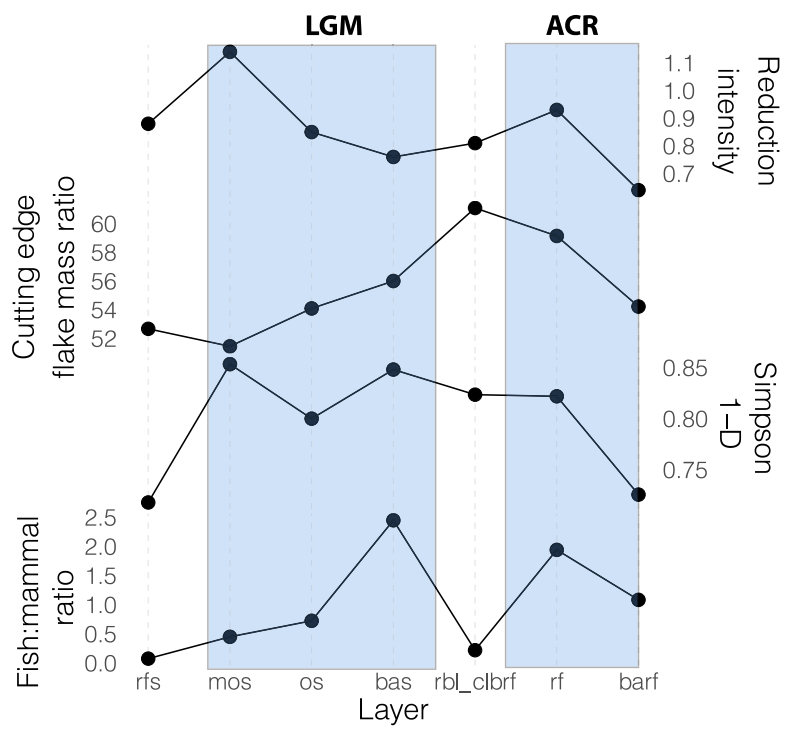

Fig. 8. Overview of the various lithic and fauna metrics showing their relative changes through the Sehonghong sequence. Blue bars represent the estimated span of two cold climatic phases, the Last Glacial Maximum (LGM) and Atlantic Cold Reversal (ACR). (For interpretation of the references to color in this figure legend, the reader is referred to the Web version of this article.)
Table 4

Correlation coefficients for comparisons of the various lithic and fauna indices. We have ommited p-values from these results as our small sample sizes (layers) preclude us accurately calculating them.

\begin{tabular}{|c|c|c|c|c|}
\hline & $\begin{array}{l}\text { Cutting } \\
\text { edge:mass }\end{array}$ & $\begin{array}{l}\text { Fish: } \\
\text { mammal }\end{array}$ & $\begin{array}{l}\text { Reduction } \\
\text { intensity }\end{array}$ & $\begin{array}{l}\text { Simpson } \\
\text { 1-D }\end{array}$ \\
\hline $\begin{array}{l}\text { Cutting edge: } \\
\text { mass }\end{array}$ & 1 & & & \\
\hline Fish:mammal & 0.26 & 1 & & \\
\hline $\begin{array}{l}\text { Reduction } \\
\text { intensity }\end{array}$ & -0.3 & -0.27 & 1 & \\
\hline Simpson 1-D & 0.3 & 0.38 & 0.5 & 1 \\
\hline
\end{tabular}

activities to coincide with fish spring/summertime spawning seasons when, "game animals are still in poor condition following winter and few plant foods are yet available." It is plausible then that fish and mammal procurement patterns will not always correlate with one another. Seasonal use of Lesotho's highland ecosystems may have offset scarcities in one or another of these resource bases.

We also need to consider the potential importance of plant food exploitation. Although plant food remains are rare at Pleistocene archeological sites, in ethnographic contexts they are known to play a role in humans' mobility and resource scheduling decisions (Kelly, 1983; also see Dusseldorp and Langejans, 2013). Binford's (2001) data show that groups living in environments with ET $<12.75$ procure, on average, $\sim 30 \%$ of their diet from gathered (plant) resources. In colder periods or regions where bulbous foods were available, they might still have comprised part of a group's subsistence intensification options. Mucina and Rutherford (2006: 373) note that the Drakensberg Basalt Grassland has "a remarkably high bulbous component". The region's available archeological and ethnographic evidence, including the ubiquitous presence of grindstones, shows that hunter-gatherers did exploit these resources (cf. Mitchell, 1995, 1996b; Eoin, 2016; Vinnicombe, 2009). Edible small-seeded plants and grasses may have provided a further subsistence intensification option in $\mathrm{C}_{4}$ vegetation belts near the Senqu River Valley.

\subsection{Unpacking complexity in the ecology and technology of Lesotho's highland hunter-gatherers}

Our data make several other valuable contributions to our understanding of highland Lesotho's hunter-gatherers. The lithic data across layers RFS, MOS, and OS ( $\sim 31-24 \mathrm{kcal} B P)$ show an inverse and bimodal pattern in which core reduction intensity is lower in layer RFS and OS and higher in layer MOS. Cutting edge to mass values show an inverse trend. The core reduction metric shows a large amplitude of variation compared to the following occupations, where the difference in cutting edge to mass is relatively small. Bipolar core frequencies are relatively low in RFS and MOS, and they pick up in layer OS (Pargeter et al., 2017). The faunal assemblages of RFS and OS are small, but they appear to reflect only occasional exploitation of aquatic resources (lower fish: mammal ratios). In the larger MOS assemblage, higher-ranked prey are more common, while fish and smaller prey remain relatively unimportant. This pattern could suggest a phase of relative "terrestrial affluence" 
in prey availability. However, the faunal evenness metric differs significantly, being very low in layer RFS and higher in layer MOS. The assemblage in layer OS is, unfortunately, very small.

Archeologists have traditionally related fauna evenness to decreased selectivity in prey exploitation (i.e., Neeley and Clark, 1993; Jones, 2004; Lupo and Schmitt, 2005). However, we could also explain the faunal evenness patterns by factors related to encounter hunting in a comparatively prosperous community of larger ungulates. The lithic reduction patterns inform on this point. They show that efforts to maximize flake numbers (higher ARI) rather than flake quality (lower cutting edge to mass) coincide with higher faunal evenness. We suggest this is likely an adaptation to a time-stressed situation that demanded abundant and readily available cutting implements (Mackay and Marwick, 2011). The lithic patterns could suggest a dynamic functional context in which the availability of cutting implements was a driving factor in technological decision making. These patterns line up with the idea that Sehonghong functioned as a dedicated large game hunting and processing station during the MOS assemblage's accumulation. Mitchell's (1994: 17) comments on layer MOS' extensive pit features that may "represent something other than the normal domestic (?) hearth, possibly a roasting pit or some other kind of special-purpose fire" support this hypothesis.

The data from the immediate layer BAS shows a lower lithic reduction intensity with higher cutting edge production rates. At the same time, fauna evenness is higher, which suggests more generalized prey exploitation than in OS (but here the comparison is hampered by layer OS's small sample size). Layer BAS' occupation also shows a dramatic increase in fishing. Rather than reflecting intensification per se, this pattern could reflect continuity in the site's use as a strategic (seasonal) hunting base, now with an emphasis on fishing, potentially of spring season spawning runs, supplemented at other times by the hunting of medium-sized ungulates. Mitchell (1995: 30) mentions layer BAS' "deep pits excavated into earlier deposit and packed solidly with charcoal" as unique and extensive features that may have been "some kind of roasting pit." The intensive use of the site may signal a similar set of functions to layer MOS, but with a different lithic reduction focus on the production of more standardized bladelets made on less heavily reduced cores (Mitchell, 1994, 1995). After the BAS occupations, hunter-gatherers may have abandoned the site for millennia (see Pargeter et al., 2017), suggesting either that environmental conditions grew increasingly difficult for highland hunter-gatherers (too difficult to be sustained by intensive aquatic resource use), or that occupation shifted to other parts of the landscape.

When occupation resumes in layer RBL/CLBRF, the lithic assemblage mirrors trends seen in layer BAS with larger amounts of flake cutting edge per mass and lower core reduction intensity. However, the subsistence indicators differ significantly. Faunal assemblage evenness remains constant, but this assemblage now comprises two especially small prey items, vlei rat, and hyrax. Plug and Mitchell (2008b) found no visible carnivore tooth or gnaw marks on the site's hyrax bones. Mitchell also excavated these bones in association with other human food remains, suggesting that they are a probable food source. Vlei rats are a common component of other faunal assemblages in Lesotho (i.e., Pitsaneng where they are $\sim 50 \%$ of QSP), suggesting that they were eaten (Plug and Mitchell, 2008a). The emphasis on small prey items shows that humans invested more energy to extract sufficient returns from a more impoverished terrestrial patch without resorting to intensive aquatic resource use.

Several lines of evidence confirm RBL-CLBRF's 'intensive' use including a substantial charcoal-rich feature similar to the one in layer BAS, higher utilized flake frequencies, intensive ochre processing, usewear suggesting the use of retouched scrapers for working hides and plant materials, and a 'cache' of worked bone implements (Mitchell, 1995). All of these activities occurred at a time when the harvesting of fish was not a priority. The reoccupation of Sehonghong at this time may represent initial forays in the highlands during warmer episodes following the toughest parts of the LGM, but outside the season when humans could exploit fish spawning runs. Fish appear to have been captured, but not mass-collected, which reduced their overall lower calorific return rate. These diminished returns led to more investment in the exploitation of other terrestrial resources, some of which, such as vlei rat, would have been easily exploited in river valleys (cf. Ugan, 2005; also see Langejans et al., 2012; Dusseldorp and Langejans, 2013). The lithic reduction strategies appear to maximize flake utility under time stress (high cutting edge to mass production), with less intensively reduced cores.

Layer RF shows a slight increase in reduction intensity coupled with decreased cutting edge production. Faunal assemblage evenness remains constant with values similar to those in layers BAS and RBL/ CLBRF. The fish:mammal ratio spikes and Mitchell (1995) notes several possible indicators of intensified onsite activities. These include several larger grindstones (some with organic residues on their surfaces), higher densities of ochre processing, a shell pendant derived from the Indian ocean ( $\sim 200 \mathrm{~km}$ east of Sehonghong), and large numbers of scrapers alongside layer RF's extensive and well-preserved plant remains (grasses, seeds and woody fragments). These hint at a more varied site occupation and intensification strategy involving plant procurement alongside lithic reduction intensity but without a major change in mammal hunting. Collectively, the combined fauna and lithic patterns show do not show the complete suite of intensification strategies predicted by Stewart and Mitchell (2018a).

Layer BARF shows a marked drop in both lithic reduction intensity and cutting edge production. The mammal prey data shows a lower overall faunal evenness index. Fish decrease dramatically in importance relative to mammalian prey. The relationship between these two indices suggests that the relative investment in mammal prey did not depend on encounter rates with different prey categories alone, but also other factors such as site function, scheduling, and the relative importance of plant and fish exploitation. The lower reduction intensity and cutting edge to mass values go along with the increased emphasis on specific prey to reflect a "return to affluence" at a time of notably warmer climates in the Lesotho highlands (Stewart and Mitchell, 2018b).

This conclusion is contradicted only by BARF's intermediate degree of fish exploitation (only superseded by BAS and RF). Mitchell (1995:29) describes layer BARF as "a thin, beige-colored, ash containing partly decayed fine grasses interpreted as bedding", which may represent a short seasonal foray into the highlands. If these forays occurred during non-spawning times, humans might have allocated more effort to mammal exploitation. This change in hunting practices would increase diet breadth, even if encounter rates with higher-ranked prey were stable. However, one could also interpret the result to show that, when mass-collected, fish shift from a lower-ranked to a higher-ranked resource. Lindstrom (1996) presents data on Great Basin fisherfolk's return rates from different fishing technologies (i.e. hook and line, spear, multiple hook, dip nets, and gill nets). Her data show, for example, how dip nets provide a substantial increase in return rates over hook and line fishing $(30.28 \mathrm{~kg} / \mathrm{h}$ versus $0.13 \mathrm{~kg} / \mathrm{h})$. Dip nets can also be left unattended while hook and line fishing requires constant attention. Choices between these different technological options affects the amount of fish taken over the period of time the fisher is actually handling the technology (i.e. how intensive the activity is). While evidence from Lesotho's Holocene rock art show hunter-gatherers used net, trap, and spear fishing technologies (Challis et al., 2008), we currently do not know what fishing methods Lesotho's highland hunter-gatherers used. Hence, the interpretation of Pleistocene fishing as an indication for intensification sensu stricto (increased investment, decreased efficiency of resource extraction, but higher total amount of resources extracted (cf. Morgan, 2015)) must be approached cautiously and with multiple working hypotheses.

The dynamics of southern Africa's Late Pleistocene climatic and environmental change make it challenging to draw simple correlations between broad environmental change and patterns of human behavior, 
occupation, and economic intensification (Gliganic et al., 2012; Eren et al., 2013: 253). Traditional culture-historical taxonomies focused on measuring superficial similarities and differences among 'microlithic' industries, and other archeologically constructed entities overlook this behaviorally significant variability. Details of humans' use of lithic technologies intersect with behavioral adaptations at local scales and 'microliths' writ so large may not be the best measure of these complex trends (Mitchell, 1988). Our data join analyses increasingly seeking to use lithics and faunal data to better understand strategic behavioral variability's role in choices of technology, human strategies for dealing with the effects of paleoenvironmental change, and their relationships to broader ecological and evolutionary processes (Scerri et al., 2014; Lycett and Von Cramon-Taubadel, 2015; O'Brien et al., 2016).

\section{Conclusions}

This study contributes to a growing body of research on the ecology and technological adaptations of Lesotho's highland hunter-gatherer groups. Here we test the hypothesis that climate change intensified these groups' diet and landscape use strategies. Our results provide mixed support for Stewart and Mitchell's (2018a) model arguing that aquatic resource intensification was linked with the broadening of hunter-gatherer diets. We find several instances in which fishing intensified irrespective of changes in mammalian procurement. Our lithic intensification indices show either weak or negative correlations with aquatic resource trends. There are several possible reasons for these mismatches. Sehonghong's layers probably aggregate several seasonal occupations that are challenging to tease apart. Diet rankings are also prone to ambiguity with, for example, fish either being lower or higher ranked resources depending on the capture method (spearing vs. mass collection in nets). "Microliths" writ large are also subject to ambiguities and can be associated with both more intensified and less intensified subsistence and land use patterns. Fish frequencies and miniaturized stone tools alone may not be reliable intensification indicators. We emphasize that prehistoric hunter-gatherers are also unlikely to have experienced the same population pressures seen in the ethnographic record. Instead, our findings show that there were multiple intensification trajectories that Lesotho's hunter-gatherers used when temperatures decreased. This strategy likely enabled groups to adapt to rapidly changing ecological contexts and to the continually evolving social environments characteristic of Late Pleistocene southern Africa.

\section{Declaration of competing interest}

The authors declare that they have no known competing financial interests or personal relationships that could have appeared to influence the work reported in this paper.

\section{Acknowledgments}

We wish to thank Peter Mitchell for generously providing access to the Sehonghong lithic assemblage and to the University of Cape Town for facilitating the data capture. Justin Pargeter's work was supported by the National Science Foundation [grant number 1542310, 2015]; the Leakey Foundation; and the Dan David Foundation. Gerrit Dusseldorp is supported through Dutch Research Council (NWO) Vidi grant 276-60004. We dedicate this paper to all the service workers and people on the frontlines of the COVID-19 pandemic and to all those in southern Africa who have made huge sacrifices in livelihood during the lockdown.

\section{Appendix A. Supplementary data}

Supplementary data to this article can be found online at https://doi. org/10.1016/j.quaint.2020.10.019.

\section{Data availability}

All data and associated statistical codes are available through the Open Science Framework registered through the following DOI 10.17605/OSF.IO/R7EKM.

\section{References}

Barton, L., Brantingham, P.J., Ji, D., 2007. Late Pleistocene Climate Change and Paleolithic Cultural Evolution in Northern China: Implications from the Last Glacial Maximum. Dev. Quat. Sci., pp. 105-128. https://doi.org/10.1016/S1571-0866(07) 09009-4. Elsevier.

Bawden, M.G., Carroll, D.M., 1968. The Land Resources of Lesotho. United Kingdom Directorate of Overseas Surveys, London.

Binford, L.R., 2001. Constructing Frames of Reference, an Analytical Method for Archaeological Theory Building Using Ethnographic and Environmental Data Sets. University of California Press, Berkeley/Los Angeles/London.

Bousman, C.B., 2005. Coping with risk: later stone age technological strategies at Blydefontein Rock Shelter, South Africa. J. Anthropol. Archaeol. 24, 193-226. https://doi.org/10.1016/j.jaa.2005.05.001.

Braun, D.R., Harris, J.W.K., 2003. Technological developments in the Oldowan of Koobi Fora: innovative techniques of artifact analysis. In: Moreno, J., Tocal, R., Sainz, I. (Eds.), Oldowan: rather More that Smashing Stones. University of Barcelona Press, Barcelona, pp. 117-144.

Carter, P.L., 1977. The Prehistory of Eastern Lesotho. Ph.D-thesis University of Cambridge, Cambridge.

Carter, P.L., Mitchellm, P.J., Vinnicombe, P., 1988. Sehonghong: the Middle and Later Stone Age Industrial Sequence at a Lesotho Rock-Shelter. BAR International Series, Oxford.

Challis, S., Mitchell, P., Orton, J., 2008. Fishing in the rain: control of rain-making and aquatic resources at a previously undescribed rock art site in highland Lesotho. J. Afr. Archaeol. 6, 203-218.

Clark, J.L., Kandel, A.W., 2013. The evolutionary implications of variation in human hunting strategies and diet breadth during the Middle Stone Age of southern Africa. Curr. Anthropol. 54, S269-S287. https://doi.org/10.1086/673386.

Dusseldorp, G.L., 2012. Studying prehistoric hunting proficiency: applying optimal foraging theory to the middle palaeolithic and middle stone age. Quat. Int. 252, 3-15. https://doi.org/10.1016/j.quaint.2011.04.024.

Dusseldorp, G.L., 2014. Explaining the Howiesons Poort to post-Howiesons Poort transition: a review of demographic and foraging adaptation models. Azania 49, 317-353. https://doi.org/10.1080/0067270X.2014.937080.

Dusseldorp, G.L., 2016. Faunal assemblage structure suggests a limited impact of the introduction of domestic stock on later stone age subsistence economies in South Africa. Afr. Archaeol. Rev. 33, 363-383. https://doi.org/10.1007/s10437-016-92298.

Dusseldorp, G.L., Langejans, G.H.J., 2013. Carry that weight: coastal foraging and transport of marine resources during the South African Middle Stone Age. South. Afr. Humanit. 25, 105-135.

Eoin, L.N., 2016. Geophytes, grasses and grindstones: replanting ideas of gathering in southern Africa's middle and later stone ages. S. Afr. Archaeol. Bull. 71, 36-45.

Eren, M.I., Diez-Martin, F., Dominguez-Rodrigo, M., 2013. An empirical test of the relative frequency of bipolar reduction in beds VI, V, and III at Mumba rockshelter, Tanzania: implications for the east African middle to late stone age transition. J. Archaeol. Sci. 40, 248-256. https://doi.org/10.1016/j.jas.2012.08.012.

Faith, J.T., Lyman, R.L., 2019. Paleozoology and Paleoenvironments: Fundamentals, Assumptions, Techniques. Cambridge University Press, Cambridge.

Finlay, B., Agresti, A., 1986. Statistical Methods for the Social Sciences. Dellen, San Franciso.

Gliganic, L.A., Jacobs, Z., Roberts, R.G., Domínguez-Rodrigo, M., Mabulla, A.Z.P., 2012. New ages for Middle and Later Stone Age deposits at Mumba rockshelter, Tanzania: optically stimulated luminescence dating of quartz and feldspar grains. J. Hum. Evol. 62, 533-547. https://doi.org/10.1016/j.jhevol.2012.02.004.

Grayson, D.K., 1991. Alpine faunas from the White Mountains, California: adaptive change in the late prehistoric great basin? J. Archaeol. Sci. 18, 483-506. https://doi, org/10.1016/0305-4403(91)90039-R.

Hammer, O., Harper, D.A.T., Ryan, P.D., 2001. PAST: paleontological statistics software package for education and data analysis. Palaeontol. Electron. 1, 9pp.

Henn, B.M., Steele, T.E., Weaver, T.D., 2018. Clarifying distinct models of modern human origins in Africa. Curr. Opin. Genet. Dev. 53, 148-156. https://doi.org/ 10.1016/j.gde.2018.10.003.

Herzog, N.M., Goodale, N., 2019. Human behavioral ecology and technological decisionmaking. In: Prentiss, A.M. (Ed.), Handbook of Evolutionary Research in Archaeology. Springer Nature Switzerland, Cham, pp. 295-309.

Jacobs, Z., Roberts, R.G., Galbraith, R.F., Deacon, H.J., Grun, R., Mackay, A., Mitchell, P., Vogelsang, R., Wadley, L., 2008. Ages for the middle stone age of southern Africa: implications for human behavior and dispersal. Science 322, 733-735. https://doi. org/10.1126/science.1162219.

Johnson, A.L., 2014. Exploring adaptive variation among hunter-gatherers with Binford's frames of reference. J. Archaeol. Res. 22, 1-42. https://doi.org/10.1007/ s10814-013-9068-y.

Jones, E.L., 2004. Dietary evenness, prey choice and human-environment interactions. J. Archaeol. Sci. 31, 307-317. https://doi.org/10.1016/j.jas.2003.08.011.

Kelly, R.L., 1983. Hunter-gatherer mobility strategies. J. Anthropol. Res. 39, 277-306. https://doi.org/10.1086/jar.39.3.3629672. 
Kelly, R.L., 2013. The Lifeways of Hunter-Gatherers: the Foraging Spectrum. Cambridge University Press, Cambridge.

Kuhn, S.L., 1992. On planning and curated technologies in the Middle Paleolithic. J. Anthropol. Res. 48, 185-214. https://doi.org/10.1086/jar.48.3.3630634.

Langejans, G.H.J., Van Niekerk, K., Dusseldorp, G.L., Thackeray, J.F., 2012. Middle stone age shellfish exploitation: evidence for mass collecting at Blombos Cave and Klasies river, South Africa. Quat. Int. 270, 80-94. https://doi.org/10.1016/j. quaint.2011.09.003.

Loftus, E., Pargeter, J., Mackay, A., Stewart, B.A., Mitchell, P., 2019. Late Pleistocene human occupation in the Maloti-Drakensberg region of southern Africa: new radiocarbon dates from Rose Cottage Cave and inter-site comparisons. J. Anthropol. Archaeol. 56, 101117. https://doi.org/10.1016/j.jaa.2019.101117.

Lupo, K.D., Schmitt, D.N., 2005. Small prey hunting technology and zooarchaeological measures of taxonomic diversity and abundance: ethnoarchaeological evidence from Central African forest foragers. J. Anthropol. Archaeol. 24, 335-353. https://doi. org/10.1016/j.jaa.2005.02.002.

Lycett, S.J., Von Cramon-Taubadel, N., 2015. Toward a "quantitative genetic" approach to lithic variation. J. Archaeol. Method Theor 22, 646-675. https://doi.org/ 10.1007/s10816-013-9200-9.

Lindstrom, S., 1996. Great Basin fisherfolk: optimal diet breadth modeling the Truckee River aboriginal subsistence fishery. In: Plew, M.G. (Ed.), Prehistoric HunterGatherer Fishing Strategies. Boise State University Press, Boise, pp. 114-179.

Lyman, R.L., 2015. On the variable relationship between NISP and NTAXA in bird remains and in mammal remains. J. Archaeol. Sci. 53, 291-296. https://doi.org/ 10.1016/j.jas.2014.10.027.

Mackay, A., 2008. A method for estimating edge length from flake dimensions: use and implications for technological change in the southern African MSA. J. Archaeol. Sci. 35, 614-622. https://doi.org/10.1016/j.jas.2007.05.013.

Mackay, A., Marwick, B., 2011. Costs and benefits in technological decision making under variable conditions: examples from the Late Pleistocene in southern Africa. In: Marwick, B., Mackay, A. (Eds.), Keeping Your Edge: Recent Approaches to the Organisation of Stone Artefact Technology. Archaeopress, Oxford, pp. 119-134.

Mackay, A., Stewart, B.A., Chase, B.M., 2014. Coalescence and fragmentation in the late Pleistocene archaeology of southernmost Africa. J. Hum. Evol. 72, 26-51. https:// doi.org/10.1016/j.jhevol.2014.03.003.

Marean, C.W., 2016. The transition to foraging for dense and predictable resources and its impact on the evolution of modern humans. Philos. Trans. Royal Soc. B: Biol. Sci. 371, 20150239. https://doi.org/10.1098/rstb.2015.0239.

Mitchell, P., 1994. Understanding the MSA/LSA transition: the pre-20 000 BP assemblages from new excavations at Sehonghong rock shelter Lesotho. Southern Afr. Field Archaeol. 3, 15-25.

Mitchell, P.J., 1995. Revisiting the Robberg: new results and a revision of old ideas at Sehonghong rock shelter, Lesotho. S. Afr. Archaeol. Bull. 50, 28-38. https://doi.org/ $10.2307 / 3889272$.

Mitchell, P.J., 1996a. The late Quaternary landscape at Sehonghong in the Lesotho highlands, southern Africa. Antiquity 70, 623-638. https://doi.org/10.1017/ S0003598X00083757.

Mitchell, P.J., 1996b. Sehonghong: the late Holocene assemblages with pottery. S. Afr. Archaeol. Bull. 51, 17-25. https://doi.org/10.2307/3888928.

Mitchell, P.J., 2008. Developing the archaeology of marine isotope stage 3. Goodwin Ser. $10,52-65$.

Morgan, C., 2015. Is it intensification yet? Current archaeological perspectives on the evolution of hunter-gatherer economies. J. Archaeol. Res. 23, 163-213. https://doi. org /10.1007/s10814-014-9079-3.

Mucina, L., Rutherford, M.C., 2006. The Vegetation of South Africa, Lesotho and Swaziland. National Botanical Institute, Pretoria.

Muller, A., Clarkson, C., 2016. Identifying major transitions in the evolution of lithic cutting edge production rates. PloS One 11, e0167244. https://doi.org/10.1371/ journal.pone.0167244.

Neeley, M.P., Clark, G.A., 1993. The Human Food Niche in the Levant over the Past 150,000 Years. Archaeological Papers of the American Anthropological Association, pp. 221-240. https://doi.org/10.1525/ap3a.1993.4.1.221.

O'Brien, M.J., Boulanger, M.T., Buchanan, B., Bentley, R.A., Lyman, R.L., Lipo, C.P., Madsen, M.E., Eren, M.I., 2016. Design space and cultural transmission: case studies from paleoindian eastern North America. J. Archaeol. Method Theor 23, 692-740. https://doi.org/10.1007/s10816-015-9258-7.
Olszewski, D.I., Schurmans, U.A., Schmidt, B.A., 2011. The Epipaleolithic (Iberomaurusian) from Grotte des Contrebandiers, Morocco. Afr. Archaeol. Rev. 28, 97-123. https://doi.org/10.1007/s10437-010-9086-9.

Pargeter, J., Loftus, E., Mitchell, P., 2017. New ages from Sehonghong rock shelter: implications for the late Pleistocene occupation of highland Lesotho. J. Archaeol. Sci.: For. Rep. 12, 307-315. https://doi.org/10.1016/j.jasrep.2017.01.027.

Parry, W.A., Kelly, R.L., 1987. Expedient core technology and sedentism. In: Johnson, J. K., Morrow, C.A. (Eds.), The Organization of Core Technology. Westview Press, Boulder, pp. 285-304.

Pleurdeau, D., Hovers, E., Assefa, Z., Asrat, A., Pearson, O., Bahain, J.-J., Lam, Y.M., 2014. Cultural change or continuity in the late MSA/Early LSA of southeastern Ethiopia? The site of Goda Buticha, Dire Dawa area. Quat. Int. 343, 117-135. https://doi.org/10.1016/j.quaint.2014.02.001.

Plug, I., 1998. Some evidence for seasonality amongst later stone age hunter-gatherers in southern Africa. Environ. Archaeol. 3, 103-107. https://doi.org/10.1179/ env.1998.3.1.103.

Plug, I., Mitchell, P., 2008a. Sehonghong: hunter-gatherer utilization of animal resources in the highlands of Lesotho. Ann. Transvaal Mus. 45, 31-53.

Plug, I., Mitchell, P., 2008b. Fishing in the Lesotho Highlands: 26,000 years of fish exploitation, with special reference to Sehonghong shelter. J. Afr. Archaeol. 6, 33-55. https://doi.org/10.3213/1612-1651-10102.

Scerri, E.M.L., Drake, N.A., Jennings, R., Groucutt, H.S., 2014. Earliest evidence for the structure of Homo sapiens populations in Africa. Quat. Sci. Rev. 101, 207-216. https://doi.org/10.1016/j.quascirev.2014.07.019.

Soffer, O., Gamble, C. (Eds.), 1990. The World at 18000 BP. Unwin Hyman, London.

Stewart, B.A., Mitchell, P., 2018a. Beyond the shadow of a desert: aquatic resource intensification on the roof of southern Africa. In: Lemke, A.K. (Ed.), Foraging in the Past. University Press of Colorado, pp. 159-208.

Stewart, B.A., Mitchell, P.J., 2018b. Late Quaternary palaeoclimates and humanenvironment dynamics of the Maloti-Drakensberg region, southern Africa. Quat. Sci. Rev. 196, 1-20. https://doi.org/10.1016/j.quascirev.2018.07.014.

Stewart, B.A., Dewar, G.I., Morley, M.W., Inglis, R.H., Wheeler, M., Jacobs, Z., Roberts, R.G., 2012. Afromontane foragers of the late Pleistocene: site formation, chronology and occupational pulsing at Melikane rockshelter, Lesotho. Quat. Int. 270, 40-60. https://doi.org/10.1016/j.quaint.2011.11.028.

Stewart, B.A., Parker, A.G., Dewar, G., Morley, M.W., Allott, L.F., 2016. Follow the Senqu: Maloti-Drakensberg paleoenvironments and implications for early human dispersals into mountain systems. In: Jones, S.C., Stewart, B.A. (Eds.), Africa from MIS 6-2: Population Dynamics and Paleoenvironments. Springer Netherlands, Dordrecht, pp. 247-271.

Stout, D., Rogers, M.J., Jaeggi, A.V., Semaw, S., 2019. Archaeology and the origins of human cumulative culture: a case study from the earliest Oldowan at Gona, Ethiopia. Curr. Anthropol. 60, 309-340. https://doi.org/10.1086/703173.

Tryon, C.A., Faith, J.T., 2016. A demographic perspective on the middle to later stone age transition from Nasera rockshelter, Tanzania. Philos. Trans. Royal Soc. B: Biol. Sci. 371, 20150238. https://doi.org/10.1098/rstb.2015.0238.

Ugan, A., 2005. Does size matter? Body size, mass collecting and their implications for understanding prehistoric foraging behaviour. Am. Antiq. 70, 75-89. https://doi. org/10.2307/40035269.

Val, A., de la Peña, P., Wadley, L., 2016. Direct evidence for human exploitation of birds in the middle stone age of South Africa: the example of Sibudu Cave, KwaZulu-Natal. J. Hum. Evol. 99, 107-123. https://doi.org/10.1016/j.jhevol.2016.07.007.

Vinnicombe, P., 2009. Basotho oral knowledge: the last Bushman inhabitants of the Mashai District, Lesotho. In: Mitchell, P., Smith, B., Vinnicombe, P. (Eds.), The Eland's People: New Perspectives in the Rock Art of the Maloti-Drakensberg Bushmen: Essays in Memory of Patricia Vinnicombe. Wits University Press, Johannesburg, pp. 165-191.

Wadley, L., 1993. The Pleistocene later stone age south of the Limpopo river. J. World Prehist. 7, 243-296. https://doi.org/10.1007/bf00974721.

\section{Further reading}

Hovers, E., Belfer-Cohen, A., 2020. Are lithics and fauna a match made in (prehistoric) heaven? J. Paleol. Archaeol. 3, 108-125. 